\title{
Designing fine-grained interactions for automation in air traffic control
}

\author{
Danwei Tran Luciani ${ }^{1}$ (1) . Jonas Löwgren ${ }^{1}$. Jonas Lundberg ${ }^{1}$
}

Received: 8 April 2019 / Accepted: 9 September 2019

(c) The Author(s) 2019

\begin{abstract}
Our work aims to explore novel approaches to the challenge of designing the interaction between people and automation. Through a case study within the domain of air traffic control, we focus on designing fine-grained human-automation interactions. We design a concept and develop an interactive lo-fi prototype of an assisted sketching system to enable air traffic controllers to interact with automation in a fine-grained manner and to externalize mental images. Assisted sketching seems to offer a possible way to communicate different degrees of predictive certainty using visual cues and interaction. Our insights further suggest that externalization through assisted sketching could encourage exploration of future scenarios, and support communication and collaboration between air traffic controllers and between air traffic controllers and pilots. The explorative benefits for the individual decision-making process might be more evident in situations where air traffic controllers have more time for reflection, for example during planning or debriefing and in educational settings.
\end{abstract}

Keywords Interaction design · Automation · Human automation collaboration · Air traffic control $\cdot$ Research-throughdesign

\section{Introduction}

In this paper, we share our work on designing for automation aiming to enable fine-grained interactions instead of using a turn-taking interaction pattern. To explain our concept of fine-grained interactions, let us use the example of how we interact with a faucet in the bathroom. By turning the handle, we immediately see the amount and feel the temperature of the running water and can thus adjust the flow and temperature to our liking. This would be what we call fine-grained interactions where continuous adjustments can be made to immediately experienced results. Compare that to a hypothetical faucet operating based on a turn-taking interaction pattern that could work something along these lines: on a separate display, numbers are manually entered to indicate the amount of water in liters per second and the temperature in degrees Celsius. A push of a button on the separate display confirms the choices and then the faucet will set the water flow accordingly. Although it is very precise, this

Danwei Tran Luciani

danwei.tran.luciani@liu.se

1 Department of Science and Technology, Linköping University, Linköping, Sweden would probably require several attempts before reaching a desired result for washing hands. The interruptions while waiting for the action of the other party is one of the downsides of turn-taking interaction patterns.

The fact that the granularity of turn-taking affects the engagement in the interaction is rather well known in human-computer interaction and has led to design principles such as direct manipulation (Shneiderman 1982) and tight coupling (Ahlberg and Shneiderman 2003). Designing for direct manipulation means to enable direct interaction with an object of interest and provide immediate visual feedback. Tight coupling is about designing the system to continuously show relevant information to support progressive refinement. However, designing fine-grained interactions for automation is not only about enabling quicker turn-taking and shorter response times. Instead it expands the focus to design for closer and simultaneous interaction with a partially agentive system. It aims to enable the system to do more than just react or respond, but to also initiate action. This way, both parties are active and get continuous feedback so that adjustments can be made without interruptions. Introducing automation into the example with the fictive faucet could, for example, enable the faucet to collaboratively adjust the water flow and temperature by sensing the reaction of the 
person touching the water. In other words, designing finegrained interactions for automation is about enabling closer and simultaneous interactions, where the parties involved fine-tune by reacting and adjusting to each other during the continuous flow of interaction.

With automation making its way into a growing number of various domains, the challenge of how to design for it remains. A dominating approach to designing for automation found in the literature seems to be by developing "models for predicting human and system performance to serve as a basis for design" (Kaber 2018, p. 7), such as the influential levels of automation framework (Sheridan and Verplank 1978) shown in Table 1.

It is interesting to note that the original intention of levels of automation was not to be a "prescription for designing automation" (Sheridan 2018). The (mis)use of levels of automation seems to advocate an interaction pattern that favors a turn-taking approach where the actions performed by people are isolated from the actions performed by the machine; the parties take turns and interact only during the handover of information (Table 2). Others have advocated to "abandon the traditional 'who does what' question of function allocation" to focus on "how to make humans and automation get along together" (Dekker and Woods 2002; Department of Defense, Defense Science Board 2012). Designing for an increase of automation should not simply mean increasing the "level of automation" by reallocating tasks from people to machine. It relies on the myth that you can reallocate functions by simple substitution or replacement (Bradshaw et al. 2013). Consequently, there is a need to explore alternatives.

We propose that a more fruitful approach to designing for increased automation could be to enable a closer interaction between people and machines, to design for simultaneous and fine-grained interactions. The concept is somewhat similar to designing for collaborative control where both parties participate in the same "function" (Fong et al. 2001), or what has been proposed as coactivity (Johnson et al. 2010). The concept of coactivity has usually been discussed in human-robot interaction where the focus is on the joint execution of shared tasks and designing a better team-member (Johnson et al. 2012). These alternative approaches move away from "function allocation by substitution"-lists with their related coarse-grained turn-taking interaction patterns that can be considered outdated in relation to contemporary technology. With fast-paced development in technological advancements, "designers cannot wait for empiricists to discover the relevant questions through theory-driven research" (Jamieson and Skraaning 2018), which also motivates design-driven approaches.

The remainder of this paper will describe and discuss our work done in a case in the domain of air traffic control. The focus has been to design fine-grained interactions for automation in air traffic control using a research-throughdesign approach.
Table 1 Levels of automation originally described in Sheridan and Verplank (1978) as a simplified model presented by Parasuraman et al. (2000)

Table 2 Turn-taking between a person and system in level 3 automation as described by Sheridan and Verplank (1978)

\begin{tabular}{lll}
\hline High & $\begin{array}{ll}\text { 10. } \\
9 .\end{array}$ & The computer decides everything, acts autonomously, ignoring the human \\
8. & The computer informs the human only if it, the computer, decides to \\
7. & The computer informs the human only if asked, or \\
6. & Allows the human a restricted time to veto before automatic execution, or \\
5. & Executes that suggestion if the human approves, or \\
4. & Suggests one alternative \\
3. & Offers a complete set of decision/action alternatives, or \\
Low & Offers no assistance: human must take all decisions and actions
\end{tabular}

\begin{tabular}{l|c} 
Description of interaction & Human functions \\
$\begin{array}{c}\text { 3. Computer helps determine } \\
\text { options and suggests one, which } \\
\text { human need not follow. }\end{array}$ & REQUESTS options \\
REQUESTS select action \\
$\begin{array}{l}\text { SELECTS action } \\
\text { (can be different) }\end{array}$ \\
START action
\end{tabular}




\section{The case: air traffic control}

The job of air traffic controllers is to direct aircraft in the air and on the ground as safely and efficiently as possible in collaboration with pilots and other air traffic controllers. To aid air traffic controllers in their tasks they have various systems and screens, for example radar displays, showing snapshots of the current traffic. Air traffic control already has quite a history with automation. There are many automated systems in place that help air traffic controllers with their daily tasks. The automated systems aim to show more accurate information, provide earlier notification of potential future conflicts between aircraft, and improve communication with pilots through datalink.

One way of designing for automation has been to allocate more of the tasks usually performed by people to the machine instead, which can create interaction patterns that we described earlier as coarse-grained turn-taking. An example is the probing function found in today's air traffic control system as shown in Fig. 1: an air traffic controller selects an aircraft to open a drop-down menu (Fig. 1
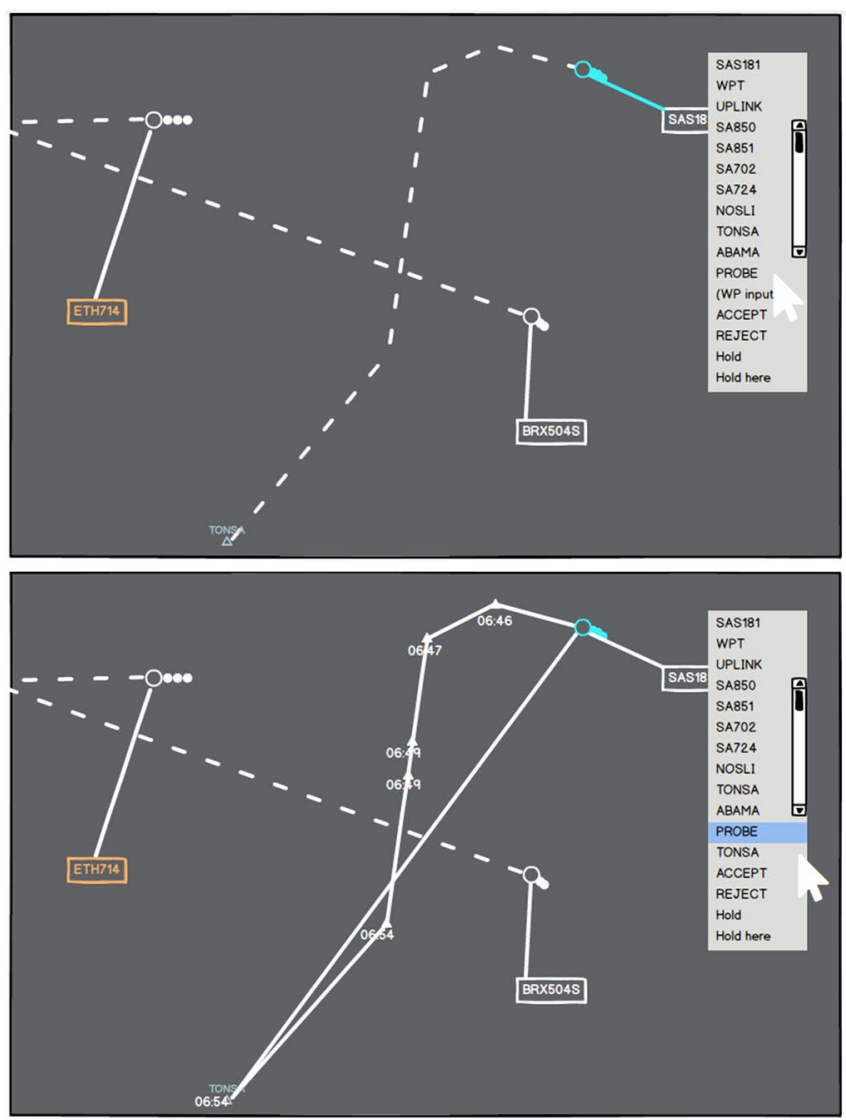

Fig. 1 Illustrations of the sequence of turn-taking in a probing function in a current air traffic control system. (Screenshots of proprietary systems were not included for confidentiality. The illustrations and top-left). Next, the probe function is chosen and "TONSA" is typed into the waypoint field below (Fig. 1 top-right). At this point, it is still only the actual flight route that is shown. To get the new probed direct route towards "TONSA" displayed, the "Enter"-key on the physical keyboard has to be pressed (Fig. 1 bottom-left). If the system detects a potential conflict caused by the probed route, the flight leg would be shown in a different color. In this case, no conflicts are detected. By clicking on "ACCEPT" below the entered waypoint in the drop-down menu, the previous route is removed (Fig. 1 bottom-right). This is an example of a coarse-grained turn-taking interaction pattern in the sense that nothing is done by both parties at the same time. Each party takes turn and has to wait for the next completed action of the other to react on (as exemplified in Table 2). It might be worth noting that this change of route is only visible to the air traffic controller who initiated the change. The updated route still needs to be communicated to the pilot of the aircraft over radio.

We believe there are potential benefits in designing an automated system that can support air traffic controllers by enabling a closer collaboration through fine-grained
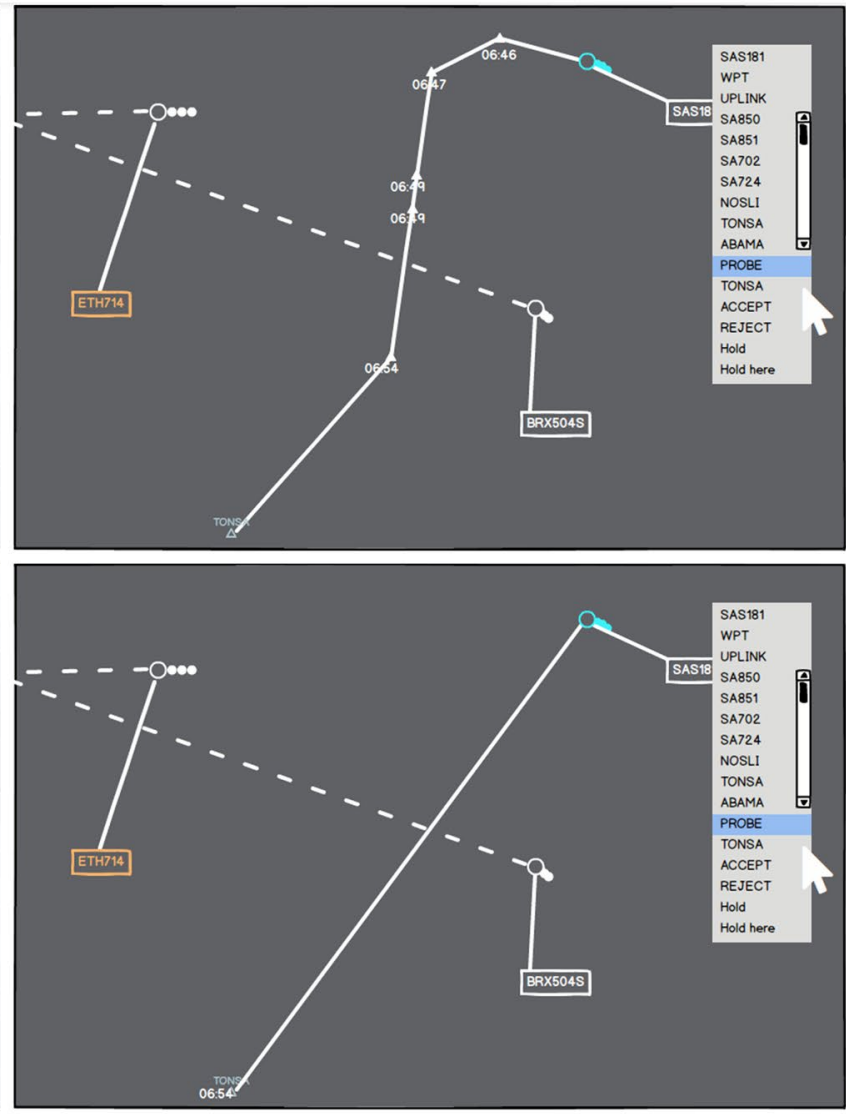

colors are based on screenshots taken from a flight simulator used by air traffic controllers for training situations. The validity of the illustrations has been confirmed by an air traffic controller.) 
interaction with the system. One way of doing that is through our concept of assisted sketching that could offer an appropriate amount of assistance and guidance. The benefits of sketching per se are well known and thoroughly documented in design research (Schon 1984; Tversky 2002). Through the act of sketching and by externalizing early ideas, benefits have been demonstrated for the individual thinking process as well as for collaboration with others, and for rhetorical purposes (Ferguson 1992; Jonson 2005; Kirsh 2010). For sketching to support thinking, collaboration and communication, it needs to be done in a manner that is quick, easy, and cheap (Buxton 2010). Quick sketches can be made using pencil and paper, but also with digital software and hardware-they are just different tools of the trade.

As our explorative design process shows (to be described in the subsequent sections), our attempt at assisted sketching is to create a system with a responsive drawing surface that uses a stylus as an input device. There are a few early examples of related works on exploring fine-grained interaction using a stylus. One example is Liquid Browsing (Waldeck and Balfanz 2004), which aims to enable browsing a large amount of data on a small screen using a stylus. With a gesture-based user interface, it introduces "liquid"-effect browsing as a way to interact with overlapping $2 \mathrm{D}$ scatter plots. Another example is BumpTop (Agarawala and Balakrishnan 2006), which recreates the experience of having a real desk in the virtual world. It is designed for pen input and simulates physical properties to make interaction with objects behave in a realistic manner, like tossing or organizing files into piles. The lack of more recent examples might indicate a loss of interest in stylus interaction, perhaps due to the explosive rise in multitouch interaction following Jeff Han's seminal work in the mid-00s (Han 2005). It might be time to pick up the stylus again because using a stylus as an interaction device can be preferable in certain contexts due to its precision and pliable feedback (Löwgren 2009).

\section{Methods: an explorative design study}

Our research deals with the design of a first-of-a-kind-system, where no previous version of the system exists to be analyzed or compared to. Thus, we do conceptual design using co-design workshops to frame and drive the design work (Lundberg et al. 2018). We take a research-throughdesign approach to generate knowledge through the process of making and reflecting (Gaver 2012; Zimmerman et al. 2007), which is necessary to explore unconventional interaction design concepts (Löwgren 2016). By creating design examples and prototypes that pose 'what if' questions, we explore possible futures. The type of knowledge contribution that can be expected from research-through-design can take the form of exemplars and intermediate-level abstractions
(Löwgren 2013). These are examples of generative knowledge that can inspire future design work for air traffic control as well as related domains. Specifically, we aim to identify a type of intermediate-level abstractions such as experiential qualities, that can inspire other researchers or practicing designers who are interested in designing fine-grained interaction between people and automation.

The explorative design study was divided into four phases, where the outcome of each phase informed and guided the direction of the next phase. In the first phase, the focus was to establish an understanding of the domain to decide how we can design for automation in air traffic control. What we learned narrowed down our focus to what the specific potential benefits of using assisted sketching to support air traffic control are, forming the basis for the subsequent formative phases to take place. The formative phases involved design work starting with a co-design workshop with air traffic controllers to pinpoint what factors affect their decision-making process, thus need to be externalized in an assisted sketching system. Next design concepts were exemplified, selected, and refined into an interactive lo-fi prototype which was later used in explorative workshop sessions with air traffic controllers.

In the following sections, we describe the explorative design study in detail. Then, we summarize the key insights and close with our reflections on the work that has been done, with comments on possible future work, and a conclusion with our tentative findings.

\section{Phase one: training course and field studies to understand the current situation}

As a preparation prior to the field studies, the first author took a 3-day-training course at Sturup airport about air traffic management to get familiar with the domain. Air traffic controllers working in tower are responsible for the traffic on the ground level at the airport and up to a certain altitude level. Above that level, the responsibility of the aircraft in transit is then handed over to air traffic controllers working in the area control. They are responsible for directing the aircraft through the airspace. The course covered the specific terminology of air traffic control and emphasized the importance of precise and predefined terms and scripted dialogues for efficient communication and limiting the risk of misunderstandings. For instance, the word "right" always refers to the direction and never means the opposite of wrong (in which case the air traffic controller would instead say "correct"). The course also included hands-on training using a simulator and gave a useful orientation for an outsider to what it is like to be an air traffic controller (Fig. 2). In modern towers, air traffic controllers have displays showing the 

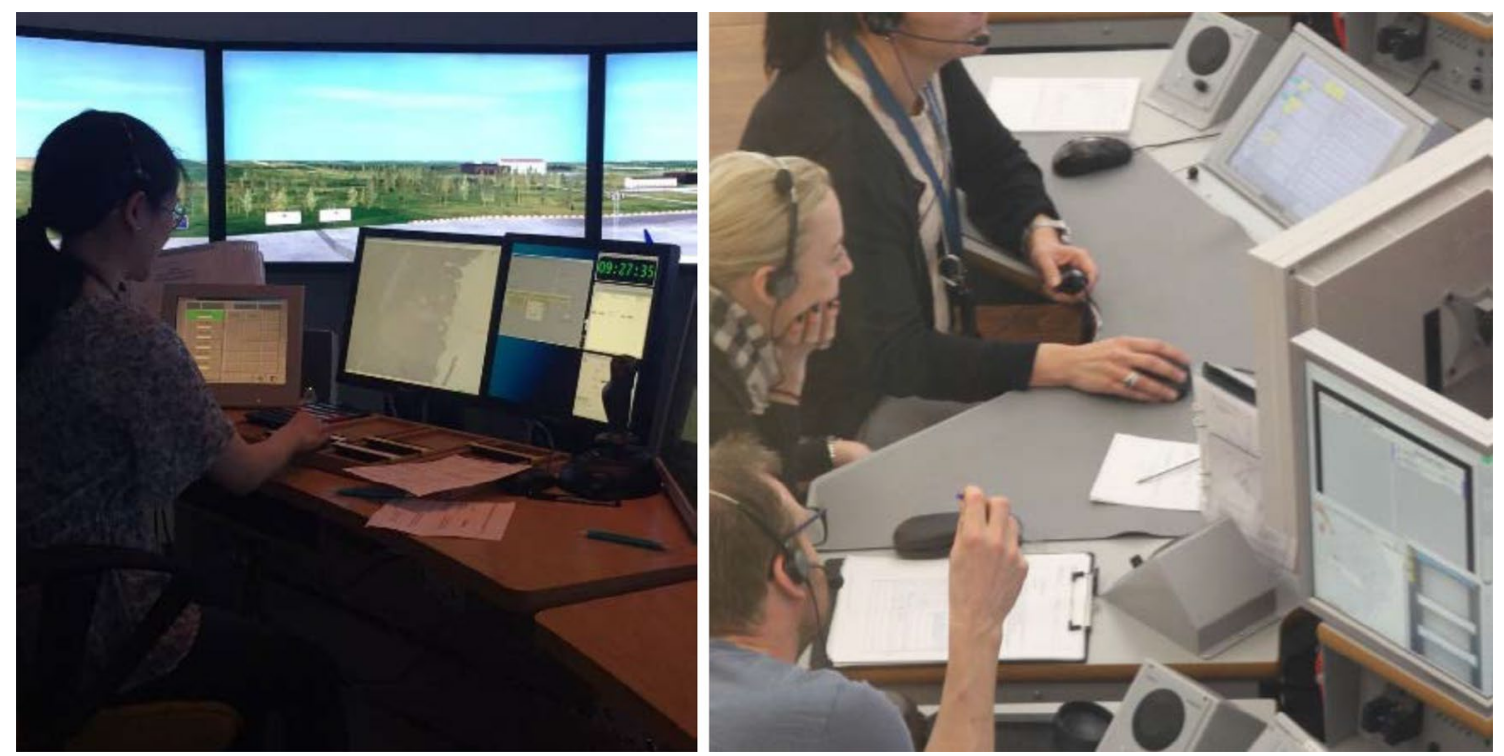

Fig. 2 The first author trying out the role of an air traffic controller using a tower simulator (left) and air traffic controllers at work in the area control (right)

current position of aircraft and vehicles on the ground in the near vicinity of the airport. In remote digital towers, the tower windows are replicated using large displays that pick up the actual view through cameras at the airports controlled by the remote tower. They also have so-called "flight strips" with aircraft identification, status, and space for manually added notes on given clearances and aircraft touchdown times. In area control, air traffic controllers mainly rely on a large radar display showing aircraft position and related information (Lundberg et al. 2014).

The first author also spent full days with air traffic controllers at their workplace, both in a control center and in a tower. During some visits, air traffic controllers were casually interviewed during their breaks between shifts, but the most insightful activity was to sit next to an air traffic controller for a whole day to observe and listen in on the radio conversations. Based on these field studies, we noted that air traffic controllers actually seem to work with a somewhat sketching mindset, but without externalization tools to support explorative planning. The job of air traffic controllers involves grasping and shaping the flows of the airspace. They continuously adjust flight paths by giving new directions to pilots depending on constantly changing factors that affect the situation. The mindset is that the latest given instruction is temporary and will need to be continuously adjusted over time. When it comes to anticipated airspace flows, air traffic controllers rely on "mental images" for the most part (Shorrock and Isaac 2010). Every air traffic controller directs aircraft to achieve an imagined future-desired state. That future state, as well as the steps towards it, exists mainly in the air traffic controller's head. (For more detailed accounts of the relation of displays and external environment versus process monitoring and planning in air traffic control, see, e.g., Lundberg 2015).

Whenever air traffic controllers are facing a specific situation to deal with, there are many possible actions that will create different outcomes. Air traffic controllers already do a great job using mental images in their heads to envision different outcomes based on their experience and to quickly choose one course of action. Their current workspace offers some support in this decision-making process, for example some systems have functions to probe what might happen if an aircraft is directed to a specific position. Air traffic controllers can probe by entering a future position for the aircraft and get a prediction from the system that warns of any potential collisions (Fig. 1). However, this kind of probing breaks the flow of their main task because of the disruptive dialogue box interaction and the requirement to designate specific positions.

With the insights gained from the field studies, we were able to identify a design opening for externalization of the decision-making process that is currently done entirely in the heads of the air traffic controllers. Due to their workload, we considered the constraints of effortlessness and swiftness with a low level of intrusion to be critical. These characteristics match those of sketching, a notion which the first author was already familiar with from previous design work and research. This in turn led to the idea of designing for assisted sketching in air traffic control, as a way to enable fine-grained interactions and externalization of mental images. 
Our first rough concept was that an assisted sketching system for air traffic controllers could consist of a responsive drawing surface superimposed on a conventional radar map. By giving pliable feedback, the system could guide the air traffic controller in the act of sketching through fine-grained interactions. It could make it more difficult for the air traffic controller to direct an aircraft towards a less desirable path, but always with a low level of intrusion. To explore this idea, further design work was conducted to build a responsive lo-fi prototype that air traffic controllers could engage with to explore its qualities.

In summary, what we found in phase one was that to enable assisted sketching, the system must make it possible to externalize and explore what matters for air traffic controllers whenever they make a decision. The field studies and recording of previous studies made by our research group gave a good overview of what air traffic controllers do in their daily work, but not why and what factors matters when they make decisions. Most of the reasoning behind their decisions is happening in their own heads. To "pick their brains", in phase two, we invited air traffic controllers to a series of individual co-design workshop sessions.

\section{Phase two: co-design workshop sessions with paperclips and paper printouts}

To pinpoint what needs to be externalized in an assisted sketching system, the first author organized individual codesign workshop sessions where tower air traffic controllers got to describe how they handle different scenarios. The workshops took place at the air traffic controllers' workplace to make it easy for them to join during their breaks between shifts. Participation was voluntary and happened spontaneously. Four experienced air traffic controllers came to the workshop and spent about 40-60 min each explaining how they work using materials provided. On a table, there were A3 printouts of the airport and the immediate space surrounding it. Next to the printouts were a variety of traditional drawing materials such as pencils, colored pens, and even watercolors and brushes (Fig. 3). The workshop sessions were recorded with audio and video from above to capture the tentative workspace created and the recordings were later transcribed and analyzed. The air traffic controllers were asked to use the available analogue materials to demonstrate and explain how they handle different air traffic scenarios. The air traffic controllers largely responded using paperclips to represent aircraft, gesturing and moving the paperclips to demonstrate possible flight routes and to explain what they were trying to achieve in different situations. They seemed to be creating flows by re-directing aircraft as the conditions changed and were always aiming toward a desired flow pictured in their minds (Fig. 4). Through experience, air traffic

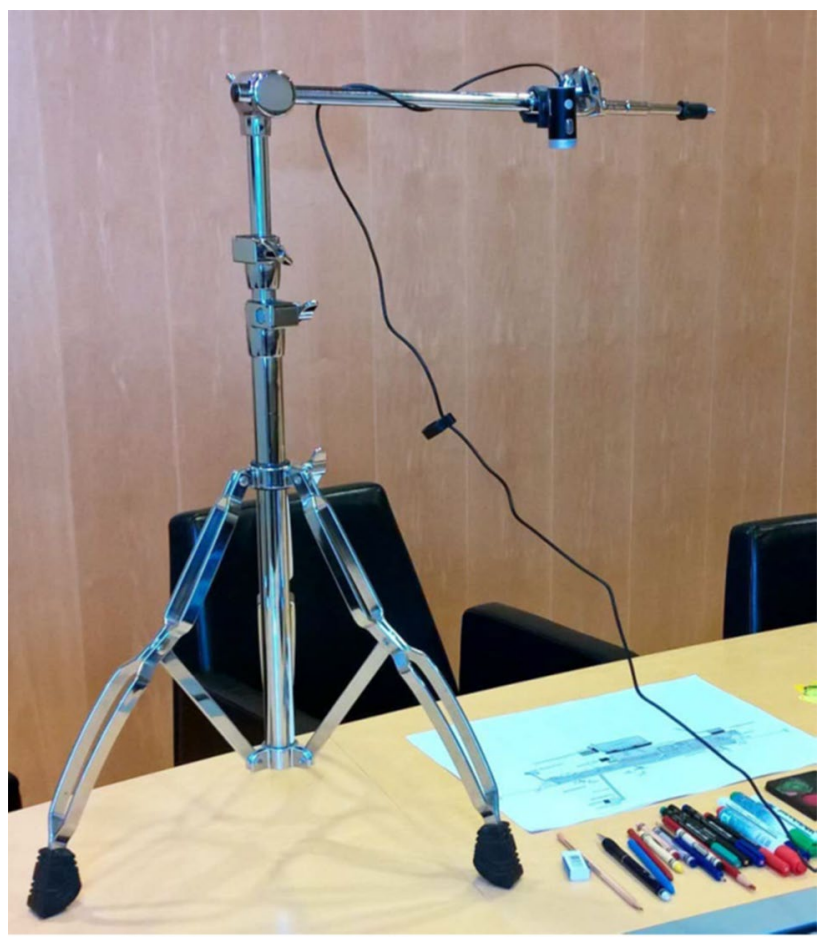

Fig. 3 The setup for the co-design workshop sessions with air traffic controllers. Paper printouts and drawing materials were placed in front of the participant and a camera was rigged to capture and record video and sound

controllers build up a repertoire of different situations, which makes them better equipped to handle the current one. A lot comes with experience, they explained, and one develops "this feeling" that enables pattern recognition. This corresponds to reliance on recognition-primed decision making (see, e.g., Klein and Calderwood 1991). It is also a direct analogy with how experienced designers build a repertoire of partial solution ideas to be used generatively in future design situations (Darke 1979).

Although the air traffic controllers were somewhat reluctant to use the traditional drawing materials provided at the workshop, they were comfortable with creating flows by constantly adjusting the paperclips. The explanation was found to be that drawing lines on the paper printouts would make them commit a flow to an immutable format, which conflicts with the dynamic nature of their work. The most obvious interpretation of the workshop outcomes would be to argue for a tangible interaction solution (Ishii and Ullmer 1997) to airspace flow planning, but we find that a slightly deeper analysis is warranted. As indicated by the qualitative data collected during the workshop, the paperclips allowed air traffic controllers to envision shaping a dynamic and responsive material. Regular pencils on paper, on the other hand, were found inadequate since they leave persistent traces and the resulting airspace flow plans become messy rather than 

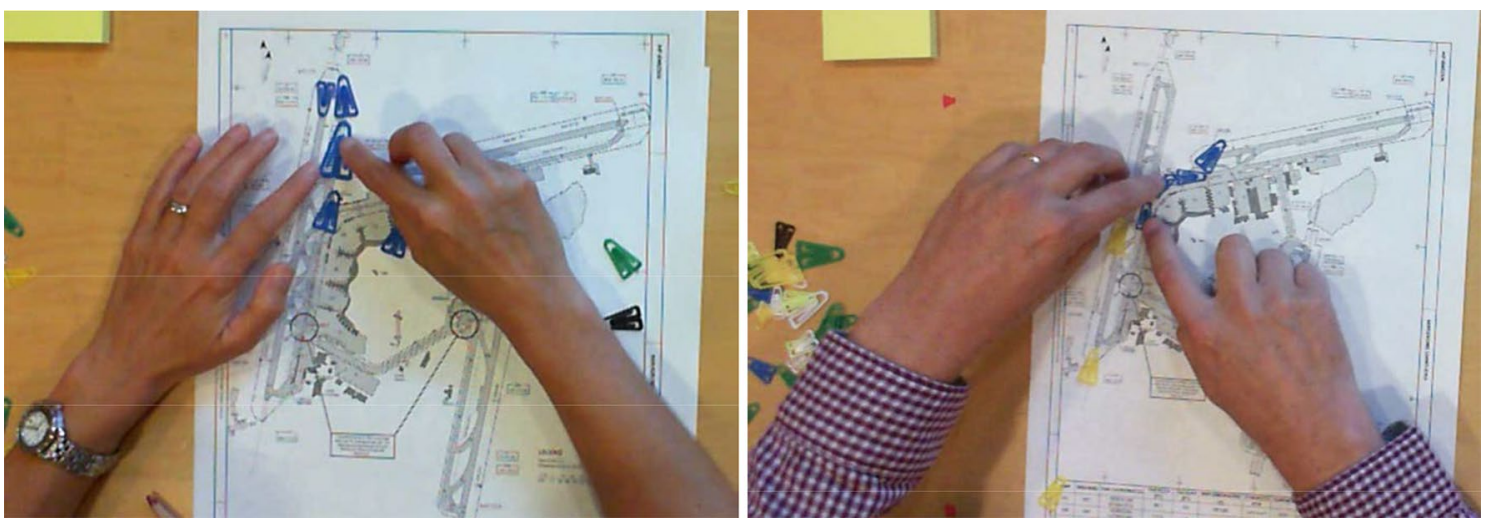

Fig. 4 Still frames from the video captures of the workshop sessions with air traffic controllers. Paperclips were used by the air traffic controllers to represent aircraft and they were laid out and constantly rearranged in a visualized dynamic flow

responsive. We took this to mean that we should orient the subsequent design work towards dynamic and responsive materials for externalizing airspace planning work. All this supported the idea of an assisted sketching system where air traffic controllers could create and manipulate dynamic route and flow representations without leaving messy traces. This does not mean that tangible interaction solutions are to be preferred since they do not inherently support intersubjective, intertemporal externalization. In other words, it is hard to save and communicate an airspace flow plan made using tangible interaction surfaces. This is a clear example of a well-known phenomenon in design, namely how co-design in lo-fi materials addresses transcendent qualities of the envisioned work rather than superficial features of interface and interaction design (Ehn 1988).

The transcripts of the individual workshops were analyzed by following a manual coding process outlined by Tesch (1990). After reading through the transcripts, interesting statements were highlighted, and notes were made in the margins. The notes helped in finding patterns and formulating categories, and the highlighted statements were then grouped accordingly. Based on the analysis, we could define the primary factors that seem to affect the air traffic controllers' decision-making process:

- Time.

- The relationship between all factors changes all the time, constantly creating new scenarios requiring continuous modification of the paths and new directions to be given by the air traffic controllers.

- Traffic situation.

- It is not only about optimizing the path for an individual aircraft, but the flow and relationship with the surrounding aircraft need to be considered at all times. The efficiency goal is to minimize the total delay of all aircraft.

- Environment and weather.
- Wind direction and strength affect the speed and turbulence of aircraft. Snow and ice can affect the condition of the runways and require a larger minimum amount of separation between aircraft. Fog, thunderstorms or other extreme weather condition can affect the sight. The information they currently get about weather is shown on a separate screen.

In other words, our design would need to make it possible to externalize and explore these listed factors for it to be useful for air traffic controllers in their decision-making process.

\section{Phase three: design concept exploration, selection, and refinement}

The core idea of assisted sketching is that the lines drawn are shaped by the air traffic controller in conjunction with the automated system. This leads to the more concrete question of how the interaction between air traffic controller and automation on the drawing surface should be constructed. Some early concepts were expressed through hand-drawn illustrations; one concept used visual inertia to guide the sketching of a path toward a more efficient one by taking into account factors such as traffic situation and weather. If one were to change the efficient path it would provide some resistance (Fig. 5a). A second concept aimed to make it possible to sketch the flow of several aircraft at the same time taking into account the overall traffic situation (Fig. 5b). A third concept took weather conditions into account, and let wind affect the steadiness of the sketching of a path (Fig. 5c). A fourth concept took time and traffic situation into account to visualize future scenarios using ghosts-of-the-future while sketching and alert on potential upcoming conflicts using collision circles (Fig. 5d). Ghosts-of-the-future is a way to directly probe future scenarios and get immediate 


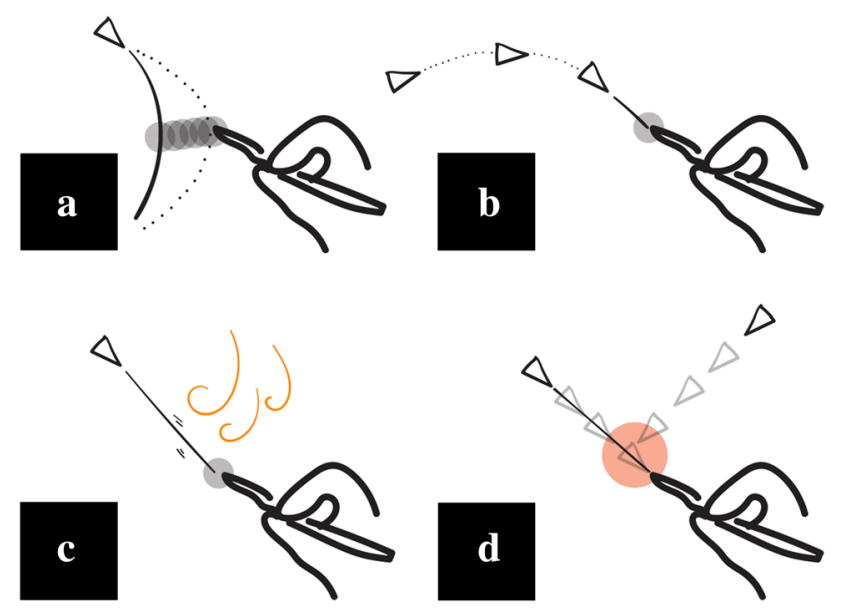

Fig. 5 Illustrations of four early interaction design concepts of assisted sketching

feedback, thanks to real-time update of all other objects in the surrounding. The aircraft with the actual position is visualized as a solid triangle in the interface, while the ghostsof-the-future of aircraft are visualized more as a shadow. The design choice was made to reflect the uncertainty of the future and to make it clear that the ghosts represent a possible future and not necessarily an exact prediction.

Illustrations and descriptive words were found insufficient to explain how some of these concepts were intended to work, for example visual inertia. It is understandable since the concept deals with unconventional interaction design and it becomes challenging to fill the gaps of the non-existing temporal details in a static illustration. A few animationbased stop-motions (Löwgren 2004; Vistisen 2016) were, therefore, made to explain the use case and they also helped us explore some of the pacing of the concept. However, the fidelity of the stop-motions was still not enough for us to explore the fine-grained interaction details, so we decided to make interactive concepts. The interactive concepts were developed in collaboration with a research engineer and written in the programming language C\# and XAML as Universal Windows Platform apps. This allowed us to run the interactive concepts on various devices and project on screens of different sizes as needed. With Git as our version control system, we could easily branch out the code to create variations of the interactive concepts. This made it possible to explore a number of concepts in parallel. Some concepts were iterated on, while others were abandoned for more promising variations. The code grew organically as we explored the different interactive concepts in isolation from each other to get a feeling for the fine-grained details of each one.

During the development of these interactive concepts, we received informal feedback from professionals within the air traffic domain. Air traffic controllers who work in the tower deals with a shorter timeframe where quick decisions need to be taken within a minute or two during busy times. Explorative sketching requires time and thus make this probably less suitable for operational work in tower where time is limited. Air traffic controllers in area control work with longer timeframes that allow for more planning ahead and they could potentially benefit from exploring several options before acting on one. Based on this type of informal feedback, we decided to focus more on features appropriate for area control. We selected the most promising implementation of each lo-fi concept, which we then combined into one single lo-fi prototype.

The lo-fi prototype ended up with a collection of the features shown in Fig. 6. There is a slider to move forward in time to see how future scenarios might play out. The future positions of aircraft are depicted as ghosts-of-the-future. They are transparent like future shadows of each aircraft to indicate possible future positions and not actual. By dragging a ghost, the route can be manipulated, and it also triggers the movement of all other ghosts making it possible to see a possible future unfold. Collision detection is shown as a red transparent circle. Changes in altitude can be made by moving a vertical slider and the altitude is depicted in the route as different sized dots. The variance in sizes of the dots indicates changes in altitude. Directing an aircraft towards obstacles gives rise to visual inertia. A screenshot can be captured by pushing a button and there is a freehand drawing option for making annotations. Another feature of the lo-fi prototype (not pictured in Fig. 6) is the possibility of creating scenarios by placing objects, drawing routes, and saving the created configurations for later use.

The features that were included in the lo-fi prototype externalize the primary factors (time, traffic situation, weather/external factors) that affect air traffic controllers' decision-making process. We then used this lo-fi prototype in a series of individual workshop sessions with air traffic controllers (see the next section).

It is a lo-fi prototype since the graphical interface was very sparse, affording room for interpretation, even though it is an interactive digital prototype (Fig. 7). The scaleddown interface without a background image was intentional to make it possible to create appropriate scenarios for air traffic controllers no matter if they work in a tower or in area control.

\section{Phase four: explorative workshop sessions with interactive lo-fi prototype}

Before the main workshop sessions, we had a 1-h preparation session with a former air traffic controller who nowadays works as an air traffic control instructor. The features of the lo-fi prototype were presented using a printout of Fig. 6 . The 
Fig. 6 The features that were implemented in the interactive lo-fi prototype

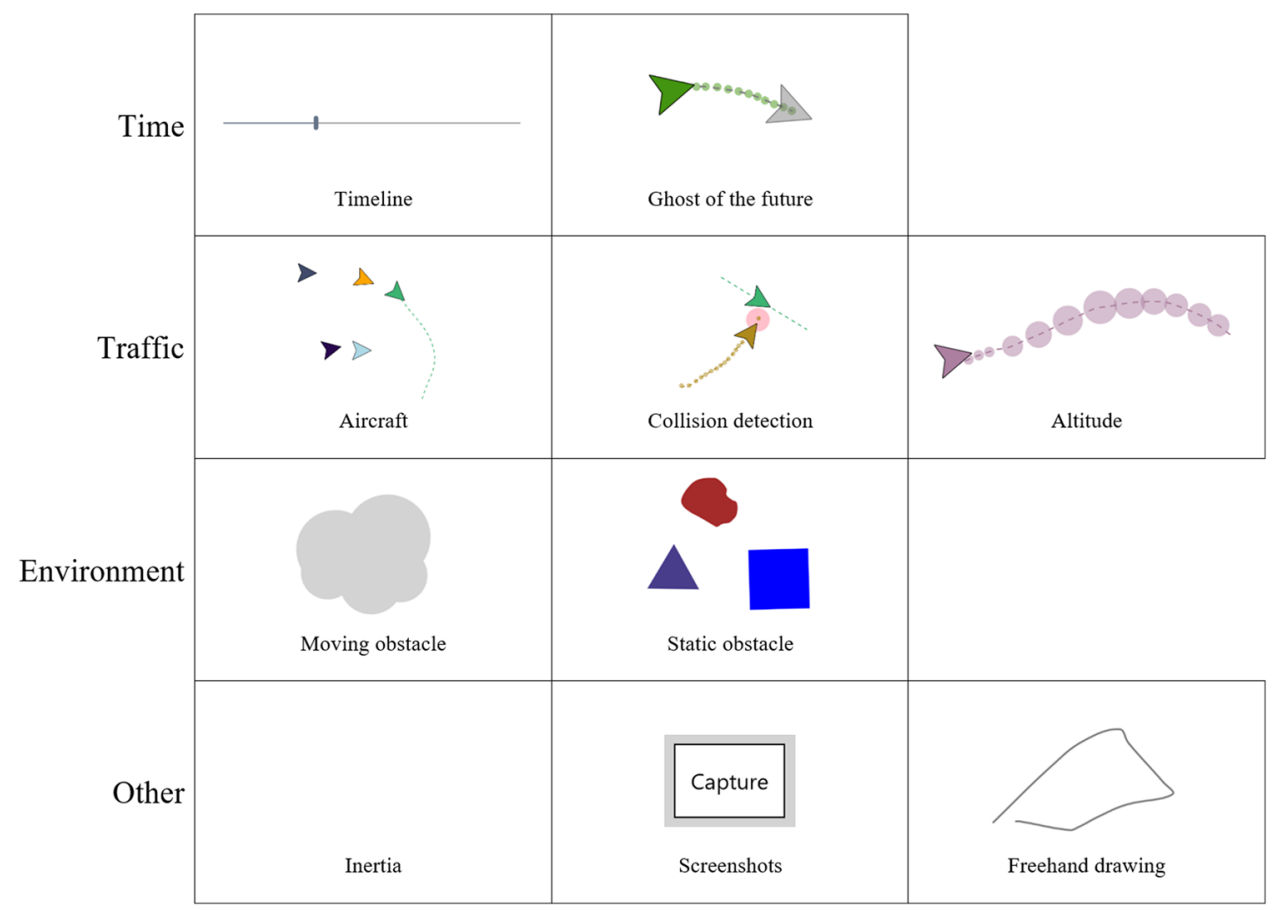

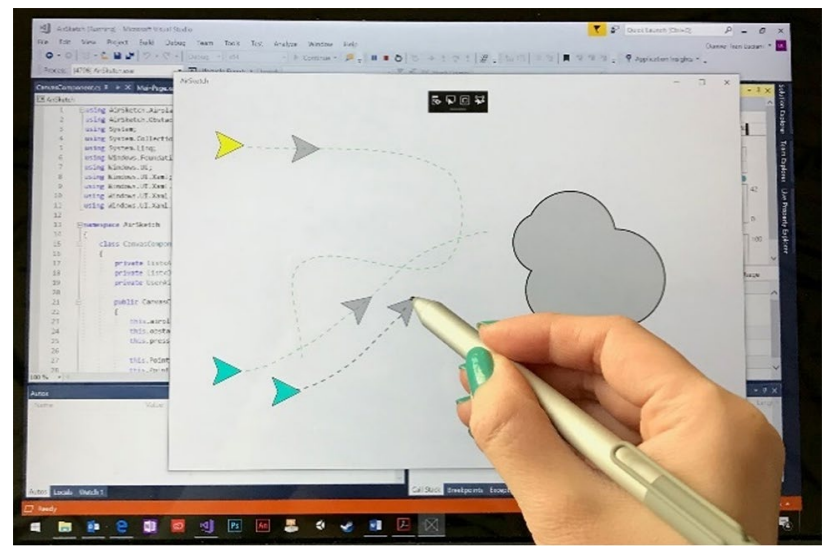

Fig. 7 The lo-fi prototype, at one point in time for exploring the finegrained interaction qualities of directing aircraft with assisted sketching

instructor got to try out the interactive lo-fi prototype and get familiar with its features by exploring freely. With the instructor's help, we created three scenarios (Figs. 8, 9, 10) to be used in the upcoming individual workshop sessions with air traffic controllers working in the area control. The instructor made sure that the scenarios were relevant in scope and made use of the features available in the lo-fi prototype.

We then carried out individual workshop sessions with four experienced air traffic controllers. None of them had participated in the previous workshops. The sessions took place in a meeting room at the air traffic controllers' workplace and participation was voluntary (Fig. 11). Each

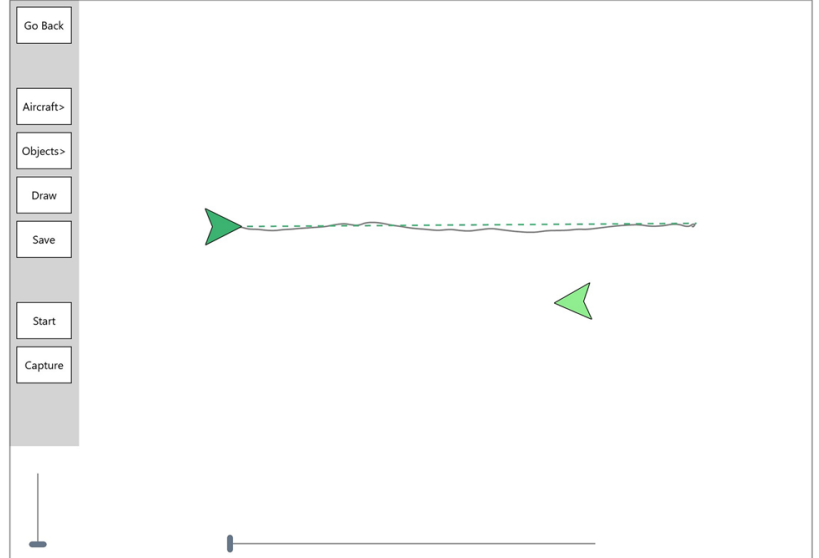

Fig. 8 Scenario one with the instruction: "Direct the second aircraft into landing"

individual session took between 30 and $40 \mathrm{~min}$. The sessions started with a walkthrough of the lo-fi prototype's features using the printout shown in Fig. 6. The air traffic controllers got familiar with the lo-fi prototype by trying out the features on their own before dealing with the three scenarios created by the instructor. The purpose of the workshop sessions was to gain insights and improve the design. It was emphasized that this was not an efficiency test of the lo-fi prototype or the air traffic controllers' ability to "solve" the scenarios. The air traffic controllers were encouraged to discuss freely around the features and reflect on potential usage in an exploratory fashion. The workshop sessions were recorded with audio 


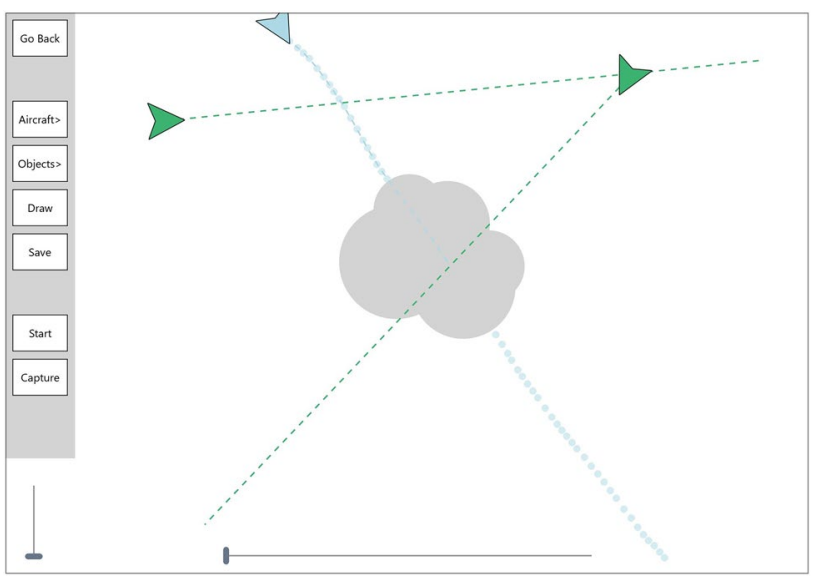

Fig. 9 Scenario two with the instruction: "A thunderstorm appears that crosses the planned routes of the aircraft. The blue aircraft requests to head East. Handle any conflicts."

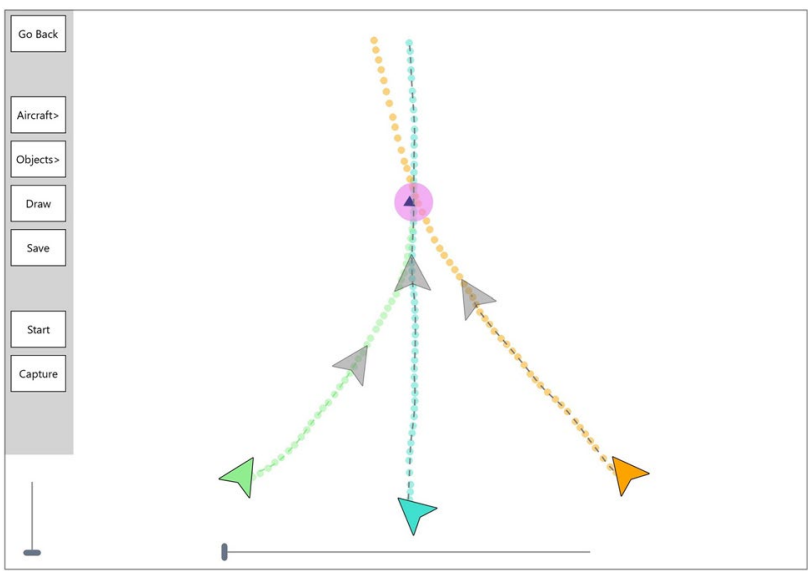

Fig. 10 Scenario three with the instruction: "Handle the sequencing"

and video from above to capture the tentative workspace. The air traffic controllers were shown the camera's field of view and could see that the video captured was only of the workspace and not of themselves. The recordings were transcribed, and interesting quotes were selected and manually coded and categorized (grouped) using thematic analysis (Tesch 1990). The insights gained from these explorative workshop sessions are presented in detail in the next section.

\section{Insights on potential benefits of using assisted sketching as a way to design for automation}

Using our lo-fi prototype, we could elicit feedback from air traffic controllers on our concept of assisted sketching. The participating air traffic controllers frequently compared it

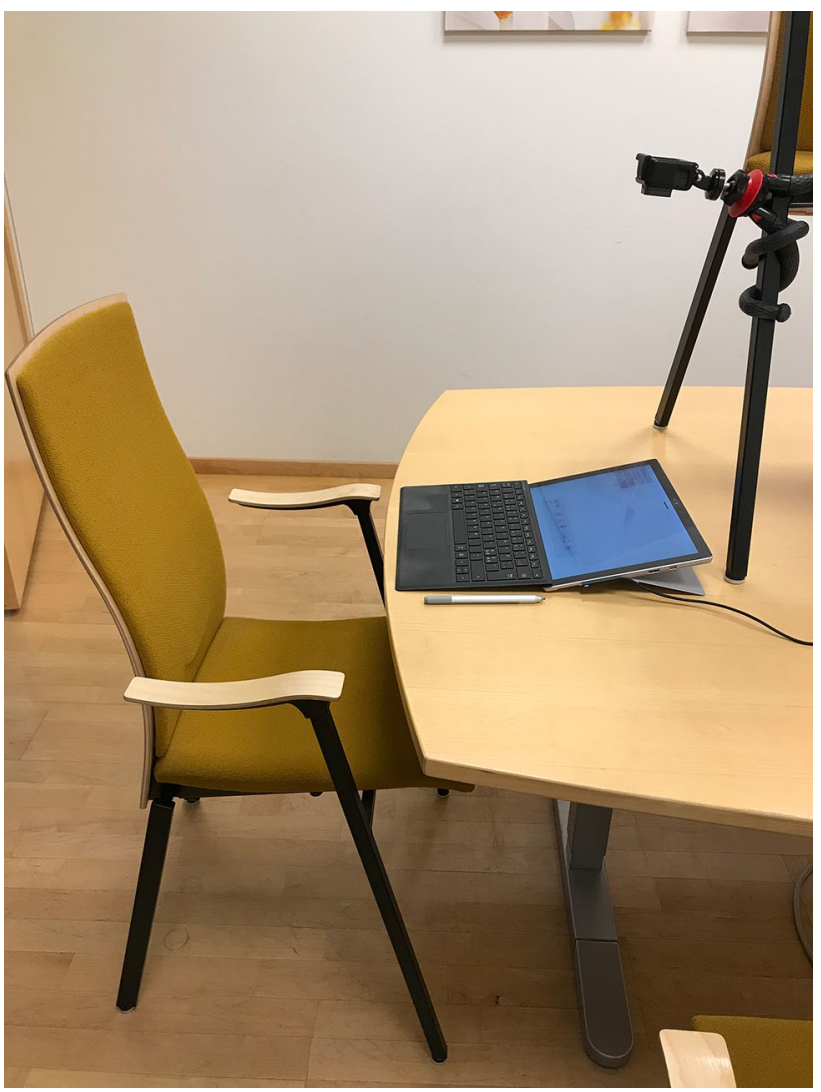

Fig. 11 The setup for the explorative workshop sessions with air traffic controllers. A surface computer running the lo-fi prototype with a stylus were placed in front the participant and a camera was rigged to capture video and sound

with their experiences with current and previous systems and referred to their daily work practices. We interpret this as our concept of assisted sketching is relevant and makes sense in this context.

The following sections describe our insights, which are both affirmative and negative regarding the concepts as we imagined them when designing the prototype. They are also generative in the sense that the air traffic controllers suggested new interpretations of what they saw and did, as well as suggesting new uses. First, assisted sketching can enable communication and guidance with different degrees of emphasis using visual cues and interactions (8.1). Second, through visual externalization of time and the ghosts-ofthe-future it can become possible to explore potential future scenarios, which could encourage exploration of alternative routes and support planning (8.2). Third, the visual externalization could support collaboration and communication between air traffic controllers when preparing hand-overs and between air traffic controllers and pilots when giving more complicated flight directions (8.3). Forth, the visual cues and interactions together with the possibility of externalization suggest potential benefits in educational settings 
and during debriefing (8.4). Fifth, a remaining challenge is how to visualize and interact with altitude. Our conceptual work did not find a promising way to inform future design work in that regard (8.5).

We describe each insight in detail in the following subsections where we refer to the instructor as 'I' and the four air traffic controllers who participated in the explorative workshop sessions as 'P0', 'P1', 'P2', and 'P3'. (Footnote: all quotes have been translated from Swedish.)

\subsection{Visual cues and interaction can support different degrees of certainty and confidence}

One fine-grained interaction detail we explored was visual inertia as a way for the assisted sketching system to guide air traffic controllers from directing aircraft towards less desirable routes. It was obvious to the air traffic controllers when the visual inertia kicked in. However, it was left to themselves to choose whether to "obey" and follow the guiding inertia or to force their way against the inertia by pulling further with the stylus. For example, when the air traffic controller tried to drag an aircraft towards a thunderstorm, the aircraft would start to lag behind the stylus, making it feel like the aircraft is resisting the direction (Fig. 12). The air traffic controller could then choose to redirect the aircraft around the thunderstorm or force it through the thunderstorm anyway by dragging further with the stylus.

"It puts up a bit of resistance, like 'Are you really gonna?'” (P1)

"It doesn't really want to follow me there. [Giggles.]" (I)

“...but this is definitely an HMI [human-machineinteraction] feature that would be... what should we call it... that it's legitimate. It would be a smart thing. [...] it definitely provides resistance like 'you shouldn't be here'. So I think that's a feature that's not so bad at all." (I)

Sometimes the inertia was combined with a transparent red colored circle to warn of a possible collision. Both the visual inertia and the collision circle seemed to encourage air traffic controllers to find alternative routes.

"Right, this was the conflict warning. Exactly. So I can't keep going. It thinks 'this was a bad move'. Yeah, I suppose that was good." [Draws a new route to avoid the conflict.] (P1)

“...so now when I give it a try... look, it warns me very well [note: the collision circles appear in two places]. 'You can't do that.' I have to do something about that, yeah [...] it didn't occur to me that they were at the same height. So that's good. That helps." (P2)

"And then if he [the aircraft] enters a new altitude 300 meters below that one, I would make him follow this path... Oh, now he [the system] thinks there is a collision..." [draws alternate route to avoid the collision.] "Let's see if I can go a bit further behind... There we go." (P2)

Unexpectedly, the collision circle seemed to assert a higher degree of emphasis and tended to evoke more "obedience". We noticed that the air traffic controllers rerouted aircraft whenever a warning circle showed up. On the other hand, they would sometimes trust their own intuition when only inertia was felt by making the aircraft go against the resistance by pulling further with the stylus.

Different visual cues and interaction thus has the potential to communicate different degrees of emphasis. This suggests that it could also be used to signify different degrees of certainty supporting variance in confidence.

\subsection{Visual externalization of time and future scenarios can support finding alternative routes}

What air traffic controllers can currently see on a radar display is the current position of aircraft, but the separation in time is not immediately visible. They use their eyes to judge the distance between them and make a judgement on when it might be appropriate to make a turn and still keep a necessary distance from nearby aircraft. We wanted to make the future more graspable using ghosts-of-the-future to play out

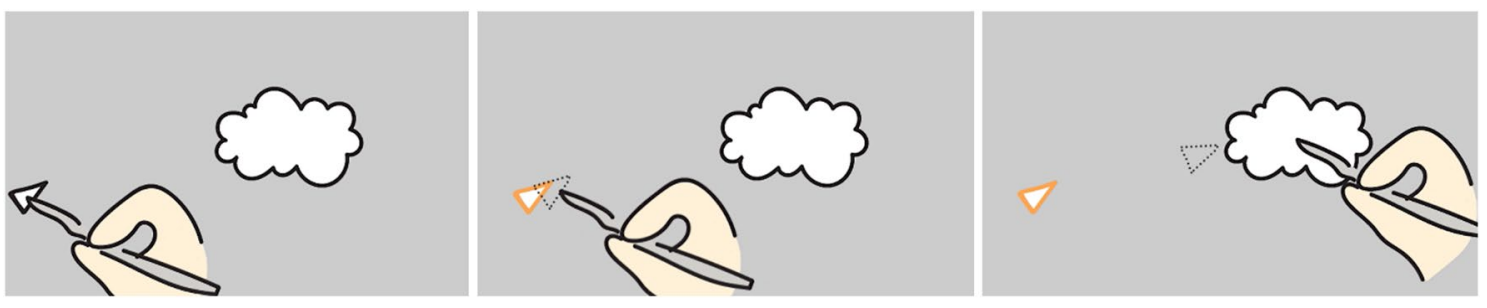

Fig. 12 Screenshots of an animation-based sketch showing the concept of visual inertia. The aircraft is resisting to be directed too close to a thunderstorm 
and interact with future possible scenarios in a more finegrained way. The air traffic controllers reacted positively to this concept, comparing it to their current tools:

"I like that you get these... that everything gets pulled forward in time automatically. So you get a 'probe' immediately. We talk about that in many projects now, about 'probing' various outcomes. 'If I follow this route, will it lead to a conflict?"” (P0)

"We already have a function called Probe and it would be quite neat if it could do something like 'if I turn this aircraft right there, what would the effect be? Will I get enough separation?' and things like that. Because, as of now, we can probe against specific waypoints so we can see 'okay yeah, if I turn right now exactly towards there, then this and this will happen. Then it will get this and this close to the other aircraft.' But we really can't place probes in the future, or you can, but it's too much of a hassle. So that's something you have to calculate in your head or go with your gut feeling." (P3)

When the air traffic controllers saw the ghosts-of-thefuture of other aircraft, they would adjust the path according to the movements of the other aircraft. This also facilitated exploration through sketching. Sometimes they would redraw the path in different ways several times before settling with their decision on how they want to direct the aircraft.

"It makes it very easy, since I see both aircraft while I'm pulling one of them, so I automatically get that future scenario, so to speak." (P0)

"Because that's also interesting, that when I draw a line, that the time comparison is shown. You see where [the other aircraft] are at the same time. [...] That simplifies a lot of things. Otherwise you'd sit here and guess that line " $\mathrm{hm}$, where will that other one be when I get there?"' (P1)

"All three of them are going toward the same [waypoint]. Since that one is last." [Starts drawing the last aircraft first and ends up not having other ghosts to adjust.] "Right course. 020 degrees... Maybe this will turn out wrong now since I'm drawing this one first..." (P2)

Ghosts-of-the-future seemed to give air traffic controllers a way to "see" time by externalizing future scenarios and visualizing the movement of all nearby aircraft. Instead of having to wait and adjust as the radar display updates in real time, this seemed to offer a way for air traffic controllers to fine-tune ahead of time.

One of the air traffic controllers emphasized that it is important that the ghosts-of-the-future show the actual "true" future, i.e., that precision is a desirable quality. It would of course be optimal if an accurate prediction model could be implemented, which is on the one hand a technical issue that relates to probe functions in general. On the other hand, perhaps it is not a make or break requirement. As long as it is possible to gauge the certainty of the prediction, the ghosts-of-the-future could still be useful even if it is not entirely accurate at all times. This is a technical and designrelated challenge that needs further exploration.

\subsection{Visual externalization can potentially support communication and collaboration}

While new systems are being developed elsewhere to support automation, all the knowledge about intention and imagined future-desired status exists only inside the individual air traffic controller's head. The air traffic controllers explained that what is known by the system (and a future system currently being developed) is the planned routes and the already given directions and clearances.

"... in this Java based HMI, which the Frenchmen will be the first to use in $2020 \ldots$ there you'll have to... it builds on the planned routes, so not on the intended route. And of course the machine can only know what's in the machine. It can't guess what's in my head.” (I)

Using the stylus and drawing the routes, the air traffic controller is feeding the system their intentions and plans, which are otherwise only kept as mental images. The air traffic controllers acknowledged the potential to use this for internal collaboration between air traffic controllers.

"But you don't know... I mean you only know the clearance that have been given. You don't necessarily know what the intent is. That's the typical thing you'd call someone up and ask about 'Hi! We have a SAS 1758. Should I direct it right or left? Do you want to keep it at that altitude?'. And maybe you could visualize some of those 'lines of thought', so to speak." (P0)

"But here maybe you'd like to immediately say 'okay, that's the point you should merge toward. This one, I want 10 miles behind it'. That's something you'd call and say'Can I have a slot there? I want 15 miles between those two.' That's something maybe you could just draw here and let the others solve it. In a good way. I imagine it could be a way to share information in a more graphical way." (P0)

"Then you'd almost need a system if you're going to delay them like that from three different directions towards the same point [...] 'You can be there with your aircraft at 02 , you can be there at 04 , you can be there at 06 . And it's very important that you're on time."” (P3) 
Further, when using the prototype, the air traffic controllers suggested that drawing routes could also be a more efficient way of giving directions to the pilot by reducing the risk of errors and omitting the need to repeat a given instruction over radio.

"We update like'okay, go on this course' and click on a waypoint with a name. Then we punch it in. Instead, you could imagine something like'I want you to fly to there, there, there' [pretends to be dotting out a path using the stylus] for example. Or just simply pull [the aircraft]." (P2)

"Yeah, that's something you could give on the same occasion 'fly like this, like this, like this, like this'. More than three is probably not optimal over radio because it easily gets complicated for the pilots to comprehend and execute on. Because you often have to confirm a lot of things and end up asking again and stuff." (P1)

"Yeah well, usually when they come here, they come here with the intention 'yeah the idea is that you should land here and you should follow this eventually, but I'll lead you on the way there'. Then you could draw a line as the instruction instead of giving five, six instructions with changing turns and speed over time.” (P1)

".... and then the rest of you follow' then I can, like you know, draw it out for everyone so they can follow the same path and then I can sequence around a weather, a shooting area in that way without having to give multiple instructions." (P1)

In summary, we explored assisted sketching as a way for air traffic controllers and automated systems to communicate and collaborate by externalizing intentions. The air traffic controllers thought that this kind of feature could also have potential to offer support in communication and collaboration between air traffic controllers themselves and with pilots. However, it is important to emphasize that collaboration between people could not be experienced directly in the lo-fi prototype during the individual workshop sessions. Further design work would be needed to explore this concept in detail.

\subsection{Visual externalization can potentially benefit education and debriefing}

The air traffic controllers suggested or acknowledged that a system with assisted sketching could be useful for air traffic controllers in training since the system could act as a tutor or a coach, providing guidance towards preferred routes.
"I like the inertia a lot because it gives a physical feedback to the students like 'no, that's not how I should do it'. And that helps you practice making the right decisions all the time. Because you want it to go fast. You can't keep going where there's resistance, you know. So, I think that's a really... that would be very efficient." (I)

"I could imagine that this would be pretty cool in educational situations as well. Just for trying out different solutions and see the consequences." (P0)

The possibility to extrapolate a specific scenario was also seen as a benefit for educational purposes and during debriefing.

"Everything gets saved. Everything gets recorded. [...] In all the sectors I've worked in, there have been recording requirements. And [the recordings] have never been used. It takes too long to go through them. You're at a debriefing and there's no time to fast forward through it. [...] Maybe you can have [the assisted sketching system] on a touchpad next to you so you can choose to push 'screenshot', and as an instructor you'd receive it afterwards and be able to retrieve them like 'okay, at this point the situation looked like this'. Usually, as a student you're pretty busy, so you may not even have noticed that particular situation." (P0)

"We conducted a study to go from the current HMI to a Java based HMI. And there, we actually had extrapolation, which is a pretty useful feature. So, the idea as such is good... and I can imagine in an educational situation that if a student chooses to give a route or a clearance that creates unnecessary conflicts, then the teacher can freeze the game and say 'okay let's see. Did you think about this?' you know, 'Were you aware of this?'. So, I definitely see how it could be useful like that." (I)

These speculations about potential use in educational and during debriefing seem fruitful, since they make for exemplary settings with time for both reflection and exploration of scenarios.

\subsection{Visual representation of altitude remains a challenge}

Separation in altitude is often used to avoid infringements but the currently used air traffic situation display is only twodimensional (an $x-y$ plot). As an air traffic controller told me "the altitude is something you visualize in your head. There is no 3D view [in the user interface]". The current altitude is 


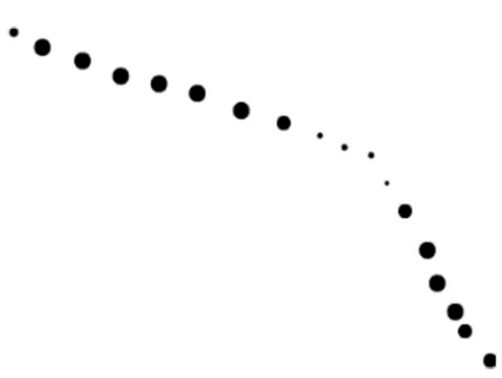

Fig. 13 Illustrated concept of how to visualize altitude directly on the planned route with the size of the dots corresponding to an altitude level of the aircraft

indicated only by a number in the label next to the aircraft. A change in the direction of where the aircraft is heading is evidently noticeable because of the animation of the aircraft while the change in altitude is just indicated by a change of a small number next to it. Our attempt at making future altitude changes visible was to use the size of each dot to represent altitude on the planned route (Fig. 13).

The idea of using varying sizes of dots was also an attempt at reducing the need for additional visual elements and make use of what was already there. However, the varying sizes seemed to be more distracting than informative to the air traffic controllers. It received unanimously negative feedback during the workshop sessions.

"On the other hand, I'm a little skeptical about that altitude change. We already see today that we have a problem with what we call 'level clutter', that's when there's too much information which makes the labels difficult to real." (I)

"To me this doesn't feel intuitive at all. [Points at the vertical slider to change altitude.] It feels really really weird. We work a lot with three dimensions. We work a lot with altitude. So to me this is a very weird representation. It doesn't really feel logical." (P3)

In addition, the variation in sizes of the dots was not precise enough compared to the number indicating the altitude level that the air traffic controllers are used to seeing on a label next to each aircraft.

"I miss the labels, of course. Just for the sake of altitude. And I think that's difficult to replace with graphics. Because you have so many flight levels. Let's say in general, from the ground and up to 40000 feet, that's 40 different layers." (P0)

"And then it's difficult to avoid using the number, you know. And it's very... it's very exact." (P3)

To summarize, our attempt at visualizing the altitude illustrates the shortcoming of an approach that lacks precision and clarity. The fact that we received some criticism from the air traffic controllers was, however, a welcome indicator that they were not solely trying please the first author who was present at the workshop sessions.

\section{Discussion and future work}

For some time, an awareness has been growing that the levels of automation framework is not a productive model to inform design work (Bradshaw et al. 2013; Dekker and Woods 2002; Department of Defense, Defense Science Board 2012), but few concrete examples of alternative ways of designing have been proposed, regarding how to design for coactivity, for example. Our work is a practical example where we describe in detail how to design for fine-grained interactions using assisted sketching as one way to enable that. Imagine for instance if we had designed the sketching interaction based on function allocation, the air traffic controller would have been able to freely draw a route and then have the automation correct it in a turn-based fashion. This could easily result in an unproductive and annoying back-and-forth correction cycle. This shortcoming has been pointed out previously, and fine-grained interaction has been proposed as more successful alternative (Lindvall et al. 2019). We introduced the concept of assisted sketching both as a critique towards coarse-grained turn-taking interaction patterns, and as a tentative design solution. The feature of visual inertia is a way to collaboratively sketch a route and could be implemented to take into account the unique characteristics of an aircraft such as its turn radius to continuously ensure the "flyability" during the act of drawing the route.

An alternative approach to design complex systems is the theoretical framework of Ecological Interface Design (Vicente and Rasmussen 1992), which usually results in interfaces with visual overlays to present constraints and boundaries (Klomp et al. 2019). This can result in overload of information, introducing visual clutter on the displays. Others have also pointed out that the ecological interface design framework, which is based on formalized workplace analysis, leaves a gap between describing what is needed and how the interface should be designed (Van Dam et al. 2008). With our approach using assisted sketching, not only do we focus on the whole interaction design rather than only the interface, but this fine-grained interaction makes it possible to create displays with less visual clutter by for example introducing the concept of visual inertia.

To explore the specific benefits of assisted sketching in air traffic control, we had to collect feedback from professional air traffic controllers. Since the concept is novel and deals with unconventional interaction design, we had to make a 
working interactive lo-fi prototype for them to experience visual inertia, ghosts-of-the-future, collision detection, and altitude changes. We invited air traffic controllers to a series of workshops where the main purpose was to collaboratively explore the concept that could inform the design work, but we also received evaluative comments and suggestions on the applicability of the different features. The interactive concept of altitude had not been through as many iterations as the other features that were included in the lo-fi prototype. It was rougher and less mature, which might have contributed to the negative feedback it got. We want to emphasize how difficult it is to imagine unconventional interaction design concepts without experiencing them, to justify the purpose of an interactive lo-fi prototype. If we had shown up with simple post-it notes and held a traditional brainstorming workshop, it would probably have been very hard for air traffic controllers to provide evaluative or generative feedback.

Considering safety regulations within air traffic control, testing this lo-fi prototype in operational use is infeasible. The results in this paper are insights drawn from a series of workshops where a limited number of professional air traffic controllers have been experiencing a lo-fi prototype in isolation from their daily workplace and colleagues. This all needs to be taken into consideration regarding how much weight the results hold. The findings should be seen as more formative rather than evaluative, and they highlight areas of interest that perhaps can inspire further explorative work. For example, the insights around potential for collaboration and communication are all speculative, but they could warrant exploring how collaborative sketching could work for this usage. The work described in this paper focuses on one case for air traffic control, but the experiential qualities of assisted sketching might be applicable in other similar cases within the domain. It could also motivate explorative work when designing for tentative planning in other transportation domains as well. As of now, automation is an area where technical advancements seem to be a few steps ahead of legal regulations. Our concept with assisted sketching, however, has the advantage of using a physical stylus which needs to be held by an air traffic controller. Nothing is modified when the air traffic controller is not actively sketching. Safety and legal aspects are top priorities within air traffic control, and the concept needs to be validated thoroughly before even suggesting it for operational use.

Apart from safety and legal aspects, there are other types of relevant research questions that researchers can form their future work around. One suggestion is to quantitatively study how the amount of visual feedback affects cognitive load and situation awareness. Another suggestion is to incorporate assisted sketching in a simulator to study how the concept affects efficiency in real-time situations for both operational and educational use. It could also be interesting to study the potential benefits of assisted sketching for varying timescales to measure the plan quality based on the need for adjustments. Further, assisted sketching can be seen as a step in the direction towards more agentive systems (Noessel 2017) incorporating machine learning aspects to adapt its behavior while it is being used. It is what Norman (1990) described as a "coaching" system. We have described elsewhere how to use machine learning as a design material to design for future air traffic control system, which could provide some inspiration on how to continue this work toward a system that learns from usage over time (Tran Luciani et al. 2018).

\section{Conclusion}

In an attempt to avoid the coarse-grained turn-taking that seems to result from using 'levels of automation' as a point of departure for design, we chose to focus on designing finegrained interactions for automation. That led us to the concept of assisted sketching. We explored some fine-grained interactions by making a lo-fi prototype and invited air traffic controllers to individual workshop sessions for formative validation. Based on the feedback and observations, we concluded that the following potential benefits can be gained with our design of assisted sketching:

- Visual cues and interaction can support different degrees of certainty and confidence.

- Visual externalization of time and future scenarios can support finding alternative routes.

- Visual externalization can potentially support communication and collaboration.

- Visual externalization can potentially benefit education and debriefing.

Our work indicates that visual representation of altitude remains a challenge.

During our work, we received feedback that made us shift to focus on scenarios when air traffic controllers were dealing with longer timeframes. The potential benefits of assisted sketching might be more evident in situations where air traffic controllers have more time for exploration and reflection, such as during planning or debriefing and in educational settings.

To conclude, this study is a practical example of a novel and alternative way of designing for automation compared to using levels of automation to inform design work.

Acknowledgements Open access funding provided by Linköping University. This work was supported by the Swedish Transport Administration (Grant number: ITN-2017-00114). 
Open Access This article is distributed under the terms of the Creative Commons Attribution 4.0 International License (http://creativeco mmons.org/licenses/by/4.0/), which permits unrestricted use, distribution, and reproduction in any medium, provided you give appropriate credit to the original author(s) and the source, provide a link to the Creative Commons license, and indicate if changes were made.

\section{References}

Agarawala A, Balakrishnan R (2006) Keepin'it real: pushing the desktop metaphor with physics, piles and the pen. In: Proceedings of the SIGCHI conference on human factors in computing systems (pp. 1283-1292). ACM

Ahlberg C, Shneiderman B (2003) Visual information seeking: tight coupling of dynamic query filters with starfield displays. In: The craft of information visualization (pp. 7-13). Morgan Kaufmann

Bradshaw JM, Hoffman RR, Woods DD, Johnson M (2013) The seven deadly myths of autonomous systems. IEEE Intell Syst 28(3):54-61

Buxton B (2010) Sketching user experiences: getting the design right and the right design. Morgan Kaufmann

Darke J (1979) The primary generator and the design process. Des Stud 1(1):36-44

Dekker SW, Woods DD (2002) MABA-MABA or abracadabra? Progress on human-automation co-ordination. Cogn Technol Work 4(4):240-244

Department of Defense, Defense Science Board (2012) Task force report: The role of autonomy in DoD systems. Office of the Undersecretary of Defense for Acquisition, Technology and Logistics, Washington

Ehn P (1988) Work-oriented design of computer artifacts (Doctoral dissertation, Arbetslivscentrum)

Ferguson ES (1992) Engineering and the Mind's eye. MIT press, Cambridge

Fong T, Thorpe C, Baur C (2001) Collaborative control: a robot-centric model for vehicle teleoperation, vol 1. Carnegie Mellon University, The Robotics Institute, Pittsburgh

Gaver W (2012) What should we expect from research through design? In: Proceedings of the SIGCHI conference on human factors in computing systems (pp. 937-946). ACM

Han JY (2005) Low-cost multi-touch sensing through frustrated total internal reflection. In: Proceedings of the 18th annual ACM symposium on User interface software and technology (pp. 115-118). ACM

Ishii H, Ullmer B (1997) Tangible bits: towards seamless interfaces between people, bits and atoms. In: Proceedings of the ACM SIGCHI Conference on human factors in computing systems (pp. 234-241). ACM

Jamieson GA, Skraaning G Jr (2018) Levels of automation in human factors models for automation design: Why we might consider throwing the baby out with the bathwater. J Cogn Eng Decis Mak 12(1):42-49

Johnson M, Bradshaw JM, Feltovich PJ, Jonker CM, Van Riemsdijk B, Sierhuis M (2010) The fundamental principle of coactive design: Interdependence must shape autonomy. In International Workshop on coordination, organizations, institutions, and norms in agent systems (pp. 172-191). Springer, Berlin

Johnson M, Bradshaw JM, Feltovich P, Jonker C, van Riemsdijk B, Sierhuis M (2012) Autonomy and interdependence in humanagent-robot teams. IEEE Intell Syst 27(2):43-51

Jonson B (2005) Design ideation: the conceptual sketch in the digital age. Des Stud 26(6):613-624
Kaber DB (2018) Issues in human-automation interaction modeling: presumptive aspects of frameworks of types and levels of automation. J Cogn Eng Decis Mak 12(1):7-24

Kirsh D (2010) Thinking with external representations. AI \& Soc 25(4):441-454

Klein GA, Calderwood R (1991) Decision-models—some lessons from the field. IEEE Trans Syst Man Cybern 21(5):1018-1026

Klomp RE, Riegman R, Borst C, Mulder M, van Paassen MM (2019) Solution space concept: human-machine interface for 4D trajectory management. In: Thirteenth USA/Europe air traffic management research and development seminar (ATM2019)

Lindvall M, Lindman K, Rose J, Sanner A, Petre F, Treanor D, Lundström C, Löwgren J (2019) TissueWand, the design of a rapid histopathology annotation tool for supervised learning

Löwgren J (2004) Animated use sketches as design representations. Interactions 11(6):22-27

Löwgren J (2009) Toward an articulation of interaction esthetics. New Rev Hypermed Multimed 15(2):129-146

Löwgren J (2013) Annotated portfolios and other forms of intermediate-level knowledge. Interactions 20(1):30-34

Löwgren J (2016) On the significance of making in interaction design research. Interactions 23(3):26-33

Lundberg J (2015) Situation awareness systems, states and processes: a holistic framework. Theor Issues Ergon Sci 16(5):447-473. https://doi.org/10.1080/1463922X.2015.1008601

Lundberg J, Johansson J, Forsell C, Josefsson B (2014) The use of conflict detection tools in air traffic management: an unobtrusive eye tracking field experiment during controller competence assurance. In: Proceedings of the International Conference on human-computer interaction in aerospace (p. 12). ACM

Lundberg J, Arvola M, Westin C, Holmlid S, Nordvall M, Josefsson B (2018) Cognitive work analysis in the conceptual design of first-of-a-kind systems-designing urban air traffic management. Behav Inf Technol 37(9):904-925

Noessel C (2017) Designing agentive technology: AI that works for people. Rosenfeld Media

Norman DA (1990) The 'problem' with automation: inappropriate feedback and interaction, not 'over-automation'. Phil Trans R Soc Lond B 327(1241):585-593

Parasuraman R, Sheridan TB, Wickens CD (2000) A model for types and levels of human interaction with automation. IEEE Trans Syst Man Cybern Part A Syst Hum 30(3):286-297

Schon DA (1984) The reflective practitioner: how professionals think in action

Sheridan TB (2018) Comments on "Issues in human-automation interaction modeling: presumptive aspects of frameworks of types and levels of automation" by David B. Kaber. J Cogn Eng Decis Mak 12(1):25-28

Sheridan TB, Verplank WL (1978) Human and computer control of undersea teleoperators. Massachusetts Inst of Tech Cambridge Man-Machine Systems Lab

Shneiderman B (1982) The future of interactive systems and the emergence of direct manipulation. Behav Inf Technol 1(3):237-256

Shorrock ST, Isaac A (2010) Mental imagery in air traffic control Int J Aviat Psychol 20(4):309-324

Tesch R (1990) Qualitative research: analysis types and software tools. Psychology Press

Tran Luciani D, Lindvall M, Löwgren J (2018) Machine learning as a design material: a curated collection of exemplars for visual interaction. DS 91: Proceedings of NordDesign 2018, Linköping, Sweden, 14th-17th August 2018

Tversky B (2002). What do sketches say about thinking. In 2002 AAAI Spring Symposium, Sketch Understanding Workshop, Stanford University, AAAI Technical Report SS-02-08 (pp. 148-151) 
Van Dam SB, Mulder M, Van Paassen MM (2008) Ecological interface design of a tactical airborne separation assistance tool. IEEE Trans Syst Man Cybern Part A Syst Hum 38(6):1221-1233

Vicente KJ, Rasmussen J (1992) Ecological interface design: theoretical foundations. IEEE Trans Syst Man Cybern 22(4):589-606

Vistisen P (2016) Sketching with animation: using animation to portray fictional realities-aimed at becoming factual. Aalborg Universitetsforlag

Waldeck C, Balfanz D (2004) Mobile liquid 2d scatter space (ml2dss). In: Proceedings of Eighth International Conference on information visualisation 2004 IV (pp. 494-498). IEEE
Zimmerman J, Forlizzi J, Evenson S (2007) Research through design as a method for interaction design research in HCI. In: Proceedings of the SIGCHI conference on human factors in computing systems (pp. 493-502). ACM

Publisher's Note Springer Nature remains neutral with regard to jurisdictional claims in published maps and institutional affiliations. 